\title{
Isocyanate-free fully biobased star polyester- urethanes: synthesis and thermal properties
}

\author{
Baptiste Quienne, ${ }^{1}$ Nejib Kasmi, ${ }^{2}$ Reiner Dieden, ${ }^{2}$ Sylvain Caillol ${ }^{1}$ and Youssef Habibi ${ }^{2 *}$ \\ ${ }^{1}$ ICGM, Univ Montpellier, CNRS, ENSCM, Montpellier, France \\ ${ }^{2}$ Materials Research and Technology Department (MRT), Luxembourg Institute of Science and \\ Technology (LIST), 5 avenue des Hauts-Fourneaux, L-4362 Esch-sur-Alzette, Luxembourg
}

Corresponding author: Youssef.Habibi@list.lu 


\title{
Graphical Abstract
}

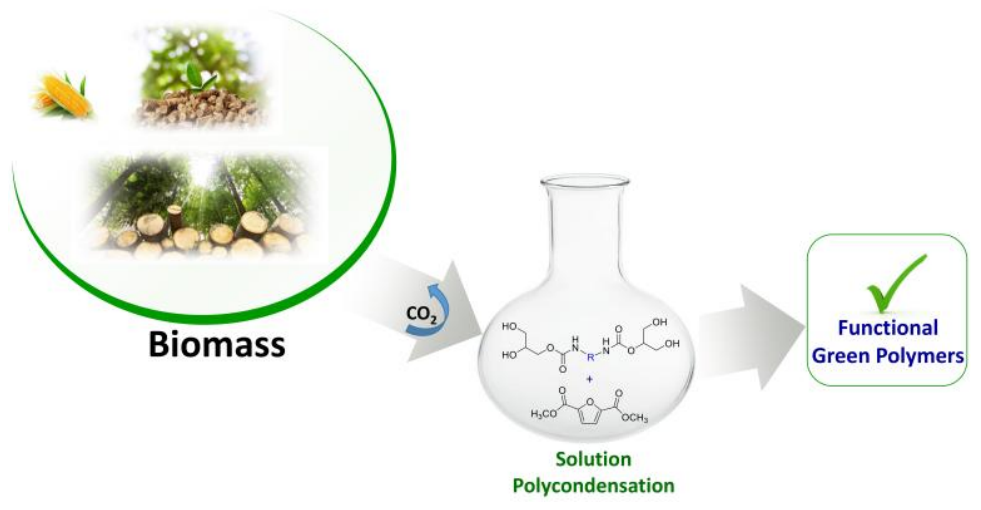

Fully biobased isocyanate free polyester-urethanes with interesting properties were prepared by combination of biobased diamine, carbon dioxide and sugar-derived diacids.

\begin{abstract}
A green strategy for the synthesis of non-isocyanate polyester-urethanes (NIPEUs) was developed. These NIPEUs were synthesized by step growth polymerization combining sugarderived dimethyl furanoic acid with polyhydroxylurethanes (PHUs) adducts bearing four hydroxyl groups. The later hydroxyl urethane tetraols (HU-tetraols) building blocks were prepared by aminolysis of glycerol carbonate with two different aliphatic amines having different chain lengths, 8 and 12 carbons. Qualitative and quantitative NMR analyses of the HU-tetraols showed the presence of primary and secondary hydroxyl moieties at different ratios. Hence, in the polycondensation stage, the stoichiometry of diacids was varied from 1 to 6 equivalents in order to tailor the structural features of the prepared NIPEUs. The success of the chain extension through polycondensation was confirmed by FTIR and NMR analyses. Thermal analyses demonstrated that these new polymers were thermally stable up to $240{ }^{\circ} \mathrm{C}$ where the main first degradation stage occurred. Their melting temperatures ranged between 90 and $110^{\circ} \mathrm{C}$ and seemed to be driven by the thermal behavior of HU-tetraol monomers. Surprisingly, preliminary
\end{abstract}


results from thermal analyses revealed the occurrence of a striking thermal change in the NIPEUs upon repetitive heating cycles. This behavior may be related to a thermal induced bond exchange probably driven by transcarbamoylation reaction. Such a potential vitrimer-like behavior for this new type of NIPEUs would be unique and should be confirmed by a deeper study before leading to a new range of functional green materials.

\section{Keywords. $\mathrm{xxx}$}

\section{Introduction}

Polyurethanes (PU) are used in a broad range of applications such as coatings, sealants, adhesives, foams, aeronautics which rank them $6^{\text {th }}$ most produced polymers in the world with 18 Mt of global production in 2016.[1, 2] PUs are known for their excellent physical and mechanical properties and are used in both thermoplastics and thermosets.[3] They are obtained by the reaction between a polyfunctional isocyanate and a polyol. However, isocyanates are harmful for human and environment, therefore their substitution has become a major concern.[4, 5] Research about non-isocyanate polyurethanes (NIPUs) has been intensively carried out by academic and industry communities during the last years.[6-8] The most promising and practical solution developed is the synthesis of PolyHydroxyUrethanes (PHUs) which are obtained by the aminolysis reaction of cyclic carbonates. Their final structure is thus composed of urethane linkage with an additional pendant hydroxyl group. Five-membered cyclic carbonates are easily synthesized by $\mathrm{CO}_{2}$ carbonation of epoxides which makes this pathway one of the most ecofriendly and the less toxic one for the synthesis of PHUs.[9-12] Indeed, the valorization of carbon dioxide which is a renewable, cheap and non-toxic resource, is a strong advantage of the 
PHU synthesis. Nevertheless, the low reactivity and conversion of carbonate/amine reaction are the main drawbacks of PHUs synthesis.[13]

To overcome this issue, recent works from our team and others on hybrid-polyhydroxyurethanes (H-PHU) allowed to obtain new properties and to improve system reactivity. Hybrid epoxypolyhydroxyurethanes are the most described in the literature and can be obtained by two different routes. The first one consists in aminolysis of a mixture of multifunctional epoxides and cyclic carbonates in a single step.[14, 15] On the other hand, amine-terminated PHU prepolymers are first synthesized with an amine excess and are then cross-linked by reacting with polyfunctional epoxy monomers in a second step.[16-18] Similarly, amine-terminated PHU have been cross-linked with other functional groups such as acrylic or methacrylic monomers. [19, 20] Hybrid siloxane-polyhydroxyurethanes thermosets have been obtained from siloxane-based cyclic carbonate monomers.[21] The low viscosity of these monomers allowed to reach high conversion and to combine flexibility of siloxanes with high mechanical properties of urethanes. However, despite these interesting reported works on end-functionalized PHUs with various functions, the use of hydroxyl groups that are easily obtained by aminolysis was never exploited to synthesize PHUs. Therefore, the aim of this study was to synthesize fully bio-based non-isocyanate poly(ester-urethane)s (NIPEU) with thermoplastic behavior. Polyesters lack of excellent physical and mechanical properties, the addition of urethane linkages in their backbone is a good way to increase their properties. To obtain NIPEUs, glycerol carbonate (GC) was reacted with two different aliphatic amines, 1,8-diaminooctane and 1,12-diaminododecane. The two HU-tetraols obtained were fully bio-based. Therefore, a second step consisted to react all hydroxyl groups of these HU-tetraols (two from GC and two from hydroxyurethane linkages) with a difunctional acid to obtain H-polyester-NIPU thermosets. The thermal and 
thermomechanical properties of these H-polyester-NIPU were investigated. This pioneered study could interestingly lead to a new range of hybrid-NIPUs.

\section{Materials and Methods}

\section{Materials}

1, 8-Diaminooctane and 1, 12-Diaminododecane were purchased from Sigma Aldrich Merck (Darmstadt, Germany). Glycerol carbonate was purchased from Huntsman (the Woodlands, TX, USA). All materials were used as received. Deuterated solvent $\mathrm{DMSO}_{\mathrm{d} 6}$ was obtained from Eurisotop for NMR study.

\section{Synthesis of HU-tetraol-C8 and HU-tetraol-C12}

In a round-bottom flask, glycerol carbonate $(2.4 \mathrm{eq}, 9.8 \mathrm{~g})$ and 1, 8-Diaminooctane $(2.0 \mathrm{eq}, 5.0 \mathrm{~g})$ were dissolved in $35 \mathrm{~mL}$ of methanol. The solution was heated at $65{ }^{\circ} \mathrm{C}$ under stirring for $5 \mathrm{~h}$. Once the solution was cooled down, the final product was precipitated in $350 \mathrm{~mL}$ of ethyl acetate at $-18{ }^{\circ} \mathrm{C}$ to remove the excess of glycerol carbonate. The powder was then washed several times with cold ethyl acetate and dried under vacuum. The pure product HU-tetraol-C8 was obtained as a white powder (yield $=98 \%$ ). The same procedure was applied for the synthesis of HUtetraol-C12.

${ }^{1} \mathrm{H}$ NMR $\delta: 1.23(\mathrm{~s}, 8 \mathrm{H}), 1.36(\mathrm{~m}, 4 \mathrm{H}), 2.94(\mathrm{~m}, 4 \mathrm{H}), 3.33(\mathrm{~m}, 2 \mathrm{H}), 3.39-3.54(\mathrm{~m}, 4 \mathrm{H}), 3.59(\mathrm{~m}$, 1H), 3.79-3.96 (m, 2H), $4.54(\mathrm{~m}, 1 \mathrm{H}) .{ }^{13} \mathrm{C} \mathrm{NMR}: \delta: 26.2\left(\mathrm{CH}_{2}-\mathrm{CH}_{2}-\mathrm{CH}_{2}\right), 29.0\left(\underline{\mathrm{CH}}_{2}-\mathrm{CH}_{2}-\mathrm{NH}\right)$, $39.5\left(\underline{\mathrm{CH}}_{2}-\mathrm{NH}\right), 60.01(\mathrm{CH}-\underline{\mathrm{CH}} 2-\mathrm{OH}), 62.8\left(\mathrm{HO}-\mathrm{CH}-\underline{\mathrm{CH}}_{2}-\mathrm{OH}\right), 65.4\left(\mathrm{O}-\underline{\mathrm{CH}}_{2}-\mathrm{CH}-\mathrm{OH}\right), 69.8$ $(\underline{\mathrm{C}} \mathrm{H}-\mathrm{OH}), 75.3\left(\mathrm{HOCH}_{2}-\underline{\mathrm{CH}}-\mathrm{CH}_{2} \mathrm{OH}\right), 156.4(\mathrm{C}=\mathrm{O})$.

\section{Polymer synthesis}


The novel NIPEUs were successfully synthesized via solution polycondensation method as follows: the predetermined amount of HU-tetraol C8 or HU-tetraol C12 and DMFD with different molar ratio of tetraol:diester of 1:1, 1:3, 1:6 were introduced in a round-bottom flask with 400 ppm of titanium(IV) butoxide (TBT) catalyst. The polyesterification was carried out in DMF under a mild nitrogen flow and heated at $90^{\circ} \mathrm{C}$ or $120^{\circ} \mathrm{C}$. At last, the reaction mixture with the reagents cooled down at room temperature and then it was precipitated in 10 volume of cold diethyl ether. The resulting polymers were again dissolved in a small amount of DMF and reprecipitated again in cold diethyl ether to ensure the elimination of unreacted compounds. The resulting polyesters are coined hereafter as follows CXX-Yeq, T. For example, C8-1eq-90 refer; where C8 stands for the tetraol C8 monomer used into the polymer synthesis, 1eq denotes the molar amount of DMFD, and 90 refers to the reaction temperature of the polycondensation.

\section{Fourier transform infrared spectroscopy (FTIR)}

FTIR was conducted on a Bruker TENSOR 27 (Ettlingen, Germany) in the attenuated total reflection (ATR) mode using a diamond crystal. The background and sample spectra were recorded at $4 \mathrm{~cm}^{-1}$ spectral resolution across the $4000-400 \mathrm{~cm}^{-1}$ range.

Nuclear magnetic resonance (NMR)

NMR spectra were recorded using an AVANCE III HD Bruker spectrometer operating at a proton frequency of $600 \mathrm{MHz}$ and equipped with a $5 \mathrm{~mm} \mathrm{BBO-probe.} \mathrm{HU-tetraols} \mathrm{adducts} \mathrm{and}$ different NIPEU polymers were dissolved in deuterated dimethyl sulfoxide (DMSO- d6). The spectra were referenced relative to tetramethylsilane (TMS). Assignments were performed using a combination of COSY, HSQC and HMBC spectra. 
Differential Scanning Calorimetry (DSC)

DSC thermograms were recorded using a METTLER TOLEDO apparatus operating at inert atmosphere (nitrogen) for the analyses of the thermal behaviour of the HU-tetraol adducts and the corresponding NIPEU-polymers. Approximately 5-7 mg of sample, sealed in aluminum pan, was heated under nitrogen from room temperature to $180{ }^{\circ} \mathrm{C}$ at a heating rate of $10{ }^{\circ} \mathrm{C} / \mathrm{min}$ then it was cooled down to $0{ }^{\circ} \mathrm{C}$ at $10{ }^{\circ} \mathrm{C} / \mathrm{min}$ and held at this temperature for 10 min to erase any thermal history and heated again for the second heating scan from $0{ }^{\circ} \mathrm{C}$ to $350{ }^{\circ} \mathrm{C}$ with a heating rate of $10^{\circ} \mathrm{C} / \mathrm{min}$.

Thermo-gravimetric analysis (TGA)

Thermogravimetry analysis measurements were performed using a METTLER TOLEDO instrument for the analyses of the thermal degradation of the HU-tetraol adducts and the corresponding NIPEU-polymers. Approximatively $10 \mathrm{mg}$ of the sample were heated under nitrogen flow from room temperature to $800{ }^{\circ} \mathrm{C}$ (heating rate $10{ }^{\circ} \mathrm{C} / \mathrm{min}$ ).

\section{Results}

\section{Synthesis of HU-tetraols}

The synthesis of $\mathrm{HU}$-tetraol was performed in methanol at $65^{\circ} \mathrm{C}$ without catalyst during $5 \mathrm{~h}$ under stirring. Two different aliphatic amines 1, 8-Diaminooctane and 1, 12-Diaminododecane were reacted with glycerol carbonate (GC) to yield respectively to HU-tetraol-C8 and HUtetraol-C12 (Figure 1). An excess of GC (2.4 eq) was reacted with amines (2 eq.) to assure a complete functionalization. A quantitative yield of HU-tetraol adducts was achieved. 

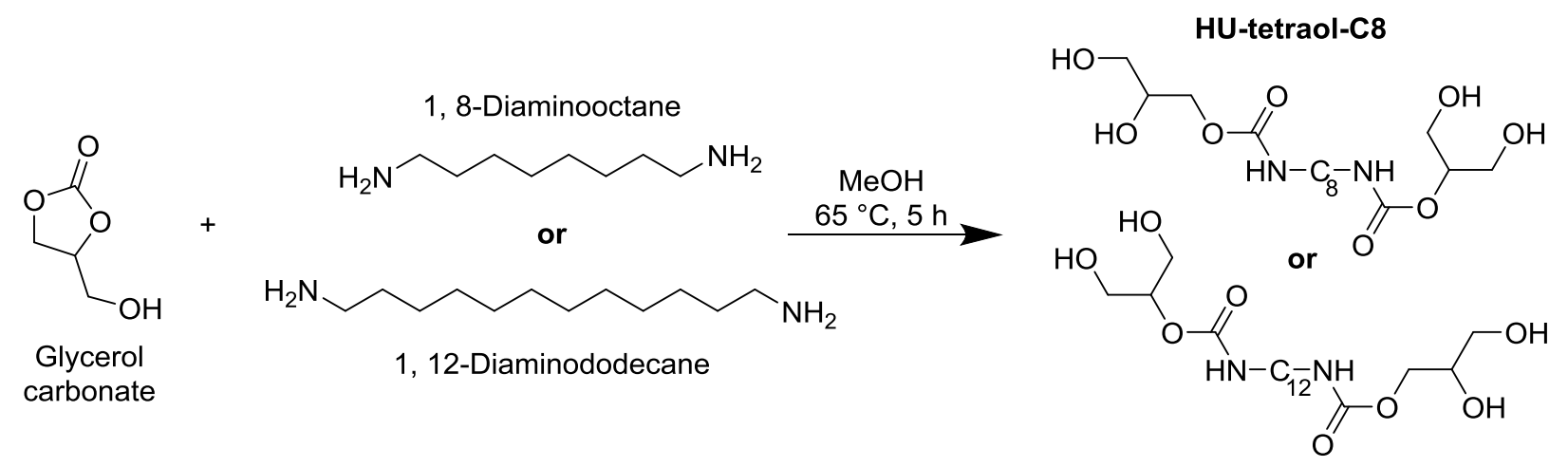

HU-tetraol-C12

Figure 1: Reaction scheme of the synthesis of HU-tetraol-C8 and HU-tetraol-C12

The success of the reaction was confirmed by NMR analyses and the full assignments of the picks was done by $2 \mathrm{D}{ }^{1} \mathrm{H}-{ }^{1} \mathrm{H}$ and ${ }^{1} \mathrm{H}_{-}{ }^{13} \mathrm{C}$ NMR which confirm the expected molecular structure of the resulting HT-tetraol adducts. The protons $c$ at $2.9 \mathrm{ppm}$ confirms the formation of the urethane linkage. Moreover, in the FTIR spectra (Figure SI-1), the band in the region of 3380$3440 \mathrm{~cm}^{-1}$ is characteristic to the NH groups of the urethane bonds. The band at $1725 \mathrm{~cm}^{-1}$ is attributed of the $\mathrm{C}=\mathrm{O}$ group of the urethane bond. The region of $1530 \mathrm{~cm}^{-1}$ shows characteristic bands for $\mathrm{CN}$ and $\mathrm{NH}$ bonds of the urethane groups. The group $\mathrm{C}-\mathrm{O}-\mathrm{C}$ can be identified by the presence of a band in $1235 \mathrm{~cm}^{-1}$. Additionally, the wave numbers of 3330,2920 and $2850 \mathrm{~cm}^{-1}$ are assigned to asymmetrical and symmetrical stretching modes of - $\mathrm{CH} 2$-group of the diamine backbone.

Quantitative NMR analyses confirmed that the ring opening aminolysis of cyclic carbonate leads predominately to the creation of secondary pendant hydroxyl groups $(\sim 80 \%)$ (proton at $3.6 \mathrm{ppm}$ labelled $e$ in Figure 2) that are thermodynamically more stable compared to primary ones.[22] The protons $h$ at $4.5 \mathrm{ppm}$ correspond to the primary alcohols that are minors. The ratio between secondary and primary alcohols was estimated by ${ }^{1} \mathrm{H}$ NMR analyses. With the integration of the 
peaks $d$ and $h$, the secondary/primary alcohol ratio were determined at $85 / 15$ and $80 / 20$ for HUtetraol-C8 and HU-tetraol-C12 respectively. These values are in accordance with the values already reported in the literature for the aminolysis of five-membered cyclic carbonate with amines.[23] Considering the primary hydroxyl groups originally present in the carbonate (at 3.33 ppm, labeled as $f$ ) the overall ratio of primary and secondary hydroxyl groups present in the HUtetraol is estimated to around 60 and $40 \%$ respectively.

This ratio is an important parameter for the synthesis polyesters using these HU-tetraols as building blocks with diacids. Indeed, primary alcohols are more reactive than secondary ones. In a view of using these HU-tetraols with diacids for the chain extension in polyesters synthesis, a special attention was given to adjustment of the ratio of alcohol to acid in order to optimize polymerization step. 


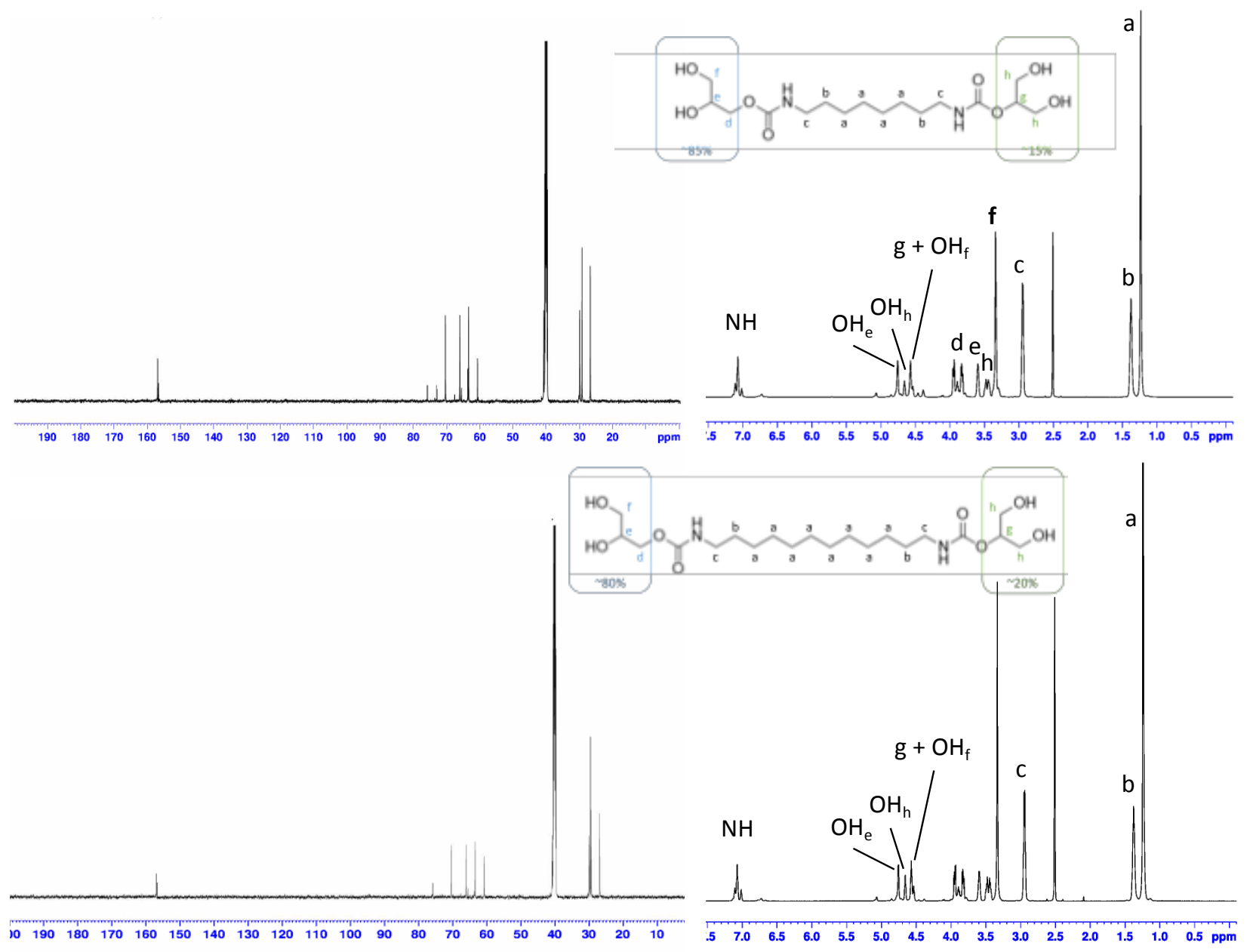

Figure 2: ${ }^{1} \mathrm{H}$ and ${ }^{13} \mathrm{C}$ NMR spectra of the HU-tetraol-C8 (top) and HU-tetraol-C12 (bottom).

The thermal properties and stability of the above synthesized HU-tetraol was checked by DSC and TGA respectively (see DSC and TGA profiles depicted in Figure SI-2). HU-tetraol C8 exhibited a melting temperature around $97{ }^{\circ} \mathrm{C}$ while the melting temperature of HU-tetraol C12 was higher $\left(122{ }^{\circ} \mathrm{C}\right)$. The (semi)crystalline structure of PHUs was largely investigated and it is accepted that the hydrogen bonding network induces such crystalline organization. No large difference in the thermal stability as well as the thermal degradation behavior was observed between the two adducts; both showed to be thermally stable up to $210^{\circ} \mathrm{C}$. The degradation 
temperature at $5 \%$ weight loss was $211^{\circ} \mathrm{C}$ for $\mathrm{HU}$-tetraol $\mathrm{C} 8$ and $221^{\circ} \mathrm{C}$ for HU-tetraol $\mathrm{C} 12$ and the remained residual weight above $500{ }^{\circ} \mathrm{C}$ ranged between 0.35 and $0.47 \%$.

The HU-tetraol building blocks were used as polyols in combination with DMFD for the synthesis of polyesters using solution step growth polymerization. Giving the chemical structure differences between the hydroxyl groups present in the HU-tetraol and their respective amount, the required feeding equivalent of the DMFD is vital to ensure the occurrence of the esterification. The effect of the temperature reaction is also an important factor. Both parameters will also influence the structural features of the resulting polymers, thus they were investigated in order to optimize the polymerization. The ratio of hydroxyl:diacid was varied from 1:1 up to 1:6 and the reaction was performed at $90{ }^{\circ} \mathrm{C}$ and $120^{\circ} \mathrm{C}$. The occurrence of the polycondensation was followed by FTIR and NMR analyses. The recorded FTIR spectra for the polymers obtained at different conditions are depicted in Figure xx. In addition to characteristic bands attributed to the different moieties of HU-tetraol adducts previously detailed (particularly urethane moieties and $\mathrm{CH} 2$ groups), additional bands typical of furanic double bonds and esters linkages appeared at around 1585 and 1710 respectively. The later overlapped with the band attributed to the urethane but it appeared clearly at higher molar ratio of DMFD (6 eq). 

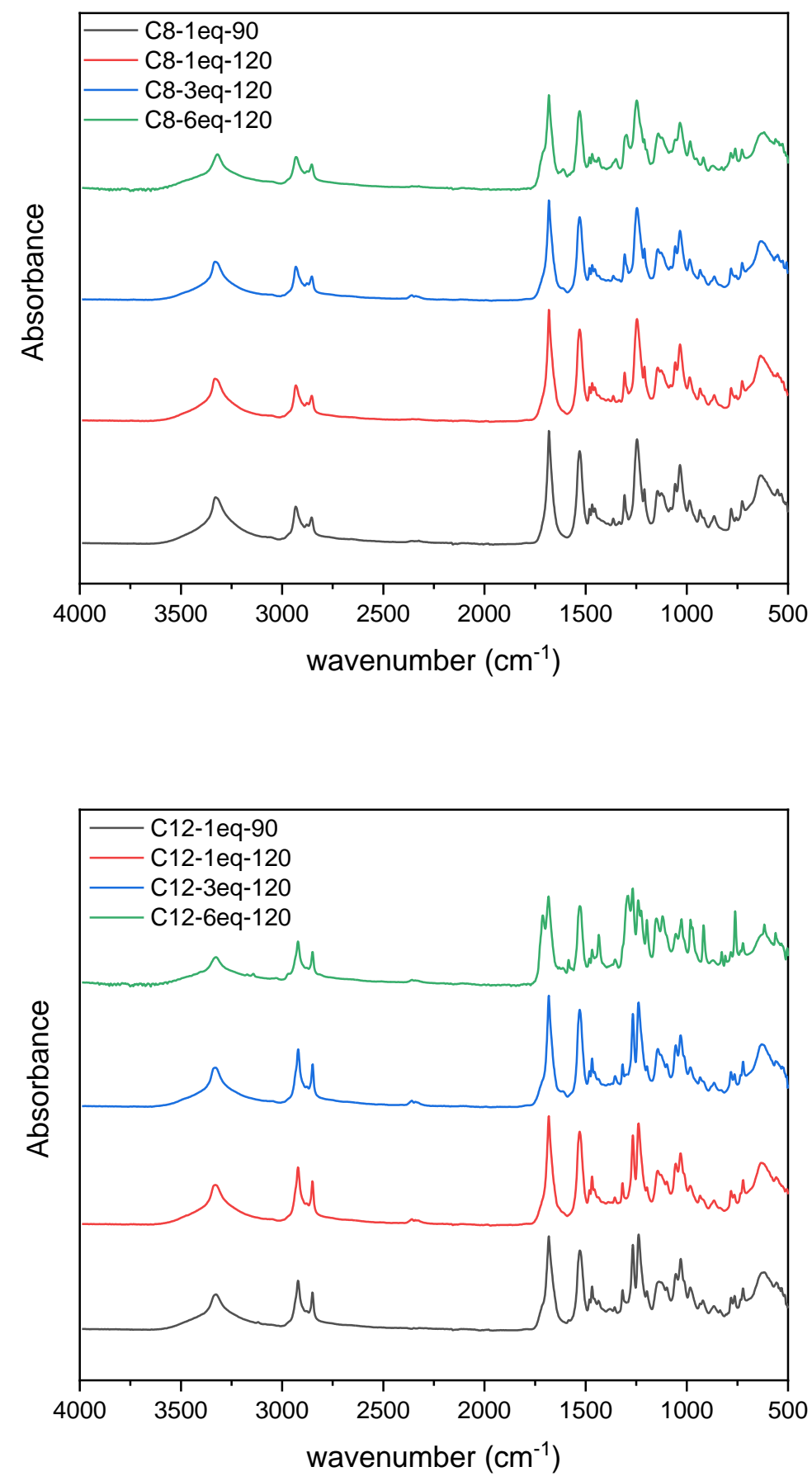

Figure xx: FTIR spectra of NIPUEs synthesized in different conditions (top with HU-tetraol C8 and bottom with HU-tetraol C12). 
These observations were further confirmed by ${ }^{1} \mathrm{H}$ and ${ }^{13} \mathrm{C}$ NMR analyses (Figure $\mathrm{xx}$ ). From structural stand point, both analyses confirmed the occurrence of the polycondensation by the presence of the characteristic peaks of the furanic moieties and ester linkages. Precisely, in ${ }^{1} \mathrm{H}$ NMR spectra one peak at $7.4 \mathrm{ppm}$ and in ${ }^{13} \mathrm{C}$ NMR two peaks at 121 and $147 \mathrm{ppm}$ are characteristics of the furan. In ${ }^{13} \mathrm{C}$ NMR spectra the presence of the peak at $165 \mathrm{ppm}$ confirms the creation of ester linkage and hence the success of the polycondensation reaction. Furthermore, the deshielding of the peaks of the protons $f$ and $h$ of HU-tetraols, attributed to primary hydroxyls, from 3.33 and 4.5 ppm respectively to $3.79-3.96$ ppm where the proton $d$ (also engaged in ester bond) of the HU-tetraol is located confirms that the esterification-driven chain extension occurs mainly on primary hydroxyl groups.
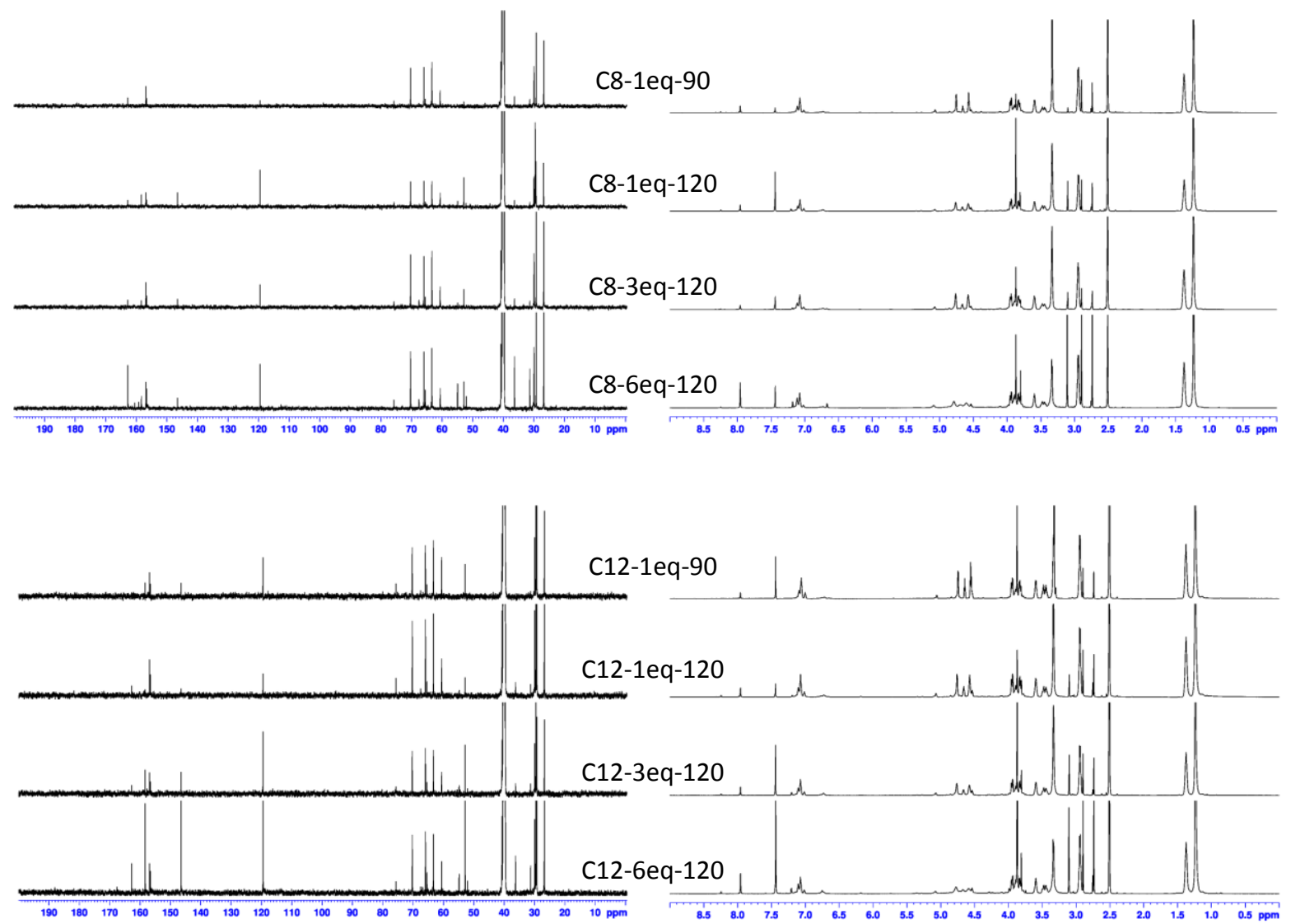
Figure 4: ${ }^{1} \mathrm{H}$ and ${ }^{13} \mathrm{C}$ NMR spectra of the NIPEU polymers synthesized at different conditions and ratio of dimethyl furan acid and HU-tetraol-C8 (top) and HU-tetraol-C12 (bottom).

The continuous decrease of the intensities of these peaks (e. g. $h$ and $f$, their respective integrals are gathered in Table 1) and well as those of the peaks related to the related $\mathrm{OH}$ located between 4.4 and $5.2 \mathrm{ppm}$ with the increase of the temperature and more particularly the increase of molar ratio of DMFD demonstrates the chain growth. Noting that the peak attributed to proton $e$ remained unchanged confirming that under the used conditions this secondary hydroxyl group didn't engage in the polycondensation reaction. It is most likely that it has been esterified once but the chain extension from this hydroxyl wasn't prolonged further.

Table 1: Integration of characteristic peak related to hydroxyl groups and adjacent protons in Hu-tetraol and furanic monomers in the polymer synthesized at different conditions.

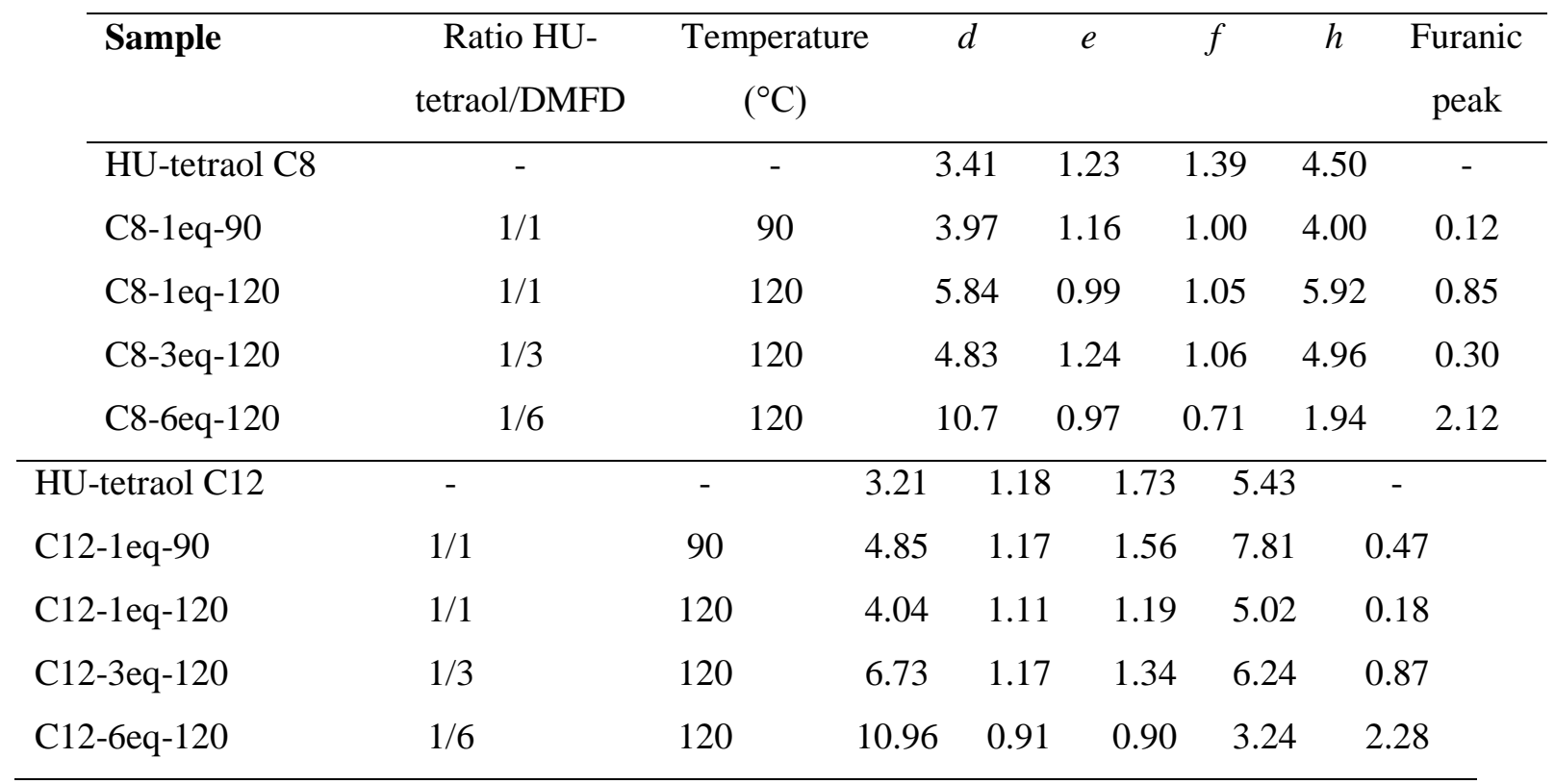


Based on the previous observations we can conclude that the three hydroxyl groups involved in the polycondensation at distinct kinetic led to branched NIPEUs most probably with low branching degree. Following the BiMolecular Non-Linear Polymerization concept (BMNLP) one can predict the structural features particularly the end groups of the synthesized polyesters.[24] This method developed by Flory and Stockmayer allows the prediction of a number of properties of the branching reaction in $a\left[a_{x}+b_{y}\right]$ system, where $x \geq 3$ and $y \geq 2$, in terms of molar ratios of the reactive groups with multiple reactive sites (3 hydroxyls and 2 acids in our case).

The critical conditions to accommodate arbitrary functionalities of the reactive monomers in an $\left[a A_{x}+b B_{y}\right]$ system are generalized in the following equation: $r p_{A}^{2} \geq 1 /(x-1)(y-1)$ with $\mathbf{r}$ as the ratio of the number of $\mathrm{A}$ and $\mathrm{B}$ groups initially present in the system and $\mathbf{p}_{\mathbf{A}}$ and $\mathbf{p}_{\mathbf{B}}$ the probability that that groups A or B respectively have reacted at any stage of the reaction between them. Hence, a soluble branched polymer can be obtained if A is the minor component when $r$ $\mathrm{p}_{\mathrm{A}}{ }^{2}>(\mathrm{x}-1)(\mathrm{y}-1)$ and if $\mathrm{B}$ is the minor component when $\mathrm{p}_{\mathrm{B}}{ }^{2} / \mathrm{r}<1 /(\mathrm{x}-1)(\mathrm{y}-1)$. For example if all $\mathrm{B}$ groups present in the $\mathrm{aA}_{\mathrm{x}}+\mathrm{bB}_{\mathrm{y}}$ system reacts, a soluble branched polymer having $\mathrm{A}$ end-groups will be formed without gelation if $r>(x-1)(y-1)$ with $r=a x / b y$ and if all A groups react, a soluble branched polymer with B end-groups will be formed if $r<1 /(1-x)(1-y)$.

In our case, one can presume that below or even up to 3 eq of diacids, the synthesized NIPEUs bear most likely hydroxyl moieties at their end groups while with 6 eq of diacids, the end groups are predominately carboxylic acid (in ester form). The signals of the end groups in both cases (hydroxyl or carboxylic groups) overlaped with the existing functionalities making very challenging the confirmation of these assumptions. To this end, in-depth NMR characterization 
using labeled molecules and/or advanced sequences are ongoing to identify and quantify these end groups.

The assessment of the thermal properties of polymeric materials is of high importance in order to evaluate their application domains. Therefore, the thermal properties of all resulting NIPEUs were investigated by TGA and DSC analyses. These properties were related to their composition (ratio HU-tertaol and DMFD). Figures $\mathrm{xx}$ present the recorded TGA thermograms and all collected data are gathered in Table 2. The data of the HU-tetraol monomers are also provided as reference.

All polymers exhibited similar degradation behaviors as they underwent three degradation stages occurring between $245-260{ }^{\circ} \mathrm{C}, 325-335{ }^{\circ} \mathrm{C}$ and $445-450{ }^{\circ} \mathrm{C}$ for HU-tetraol-C8 and 235-264, 330-338 and $450-455{ }^{\circ} \mathrm{C}$ for HU-tetraol-C12. These degradations are typical of dehydration, decarboxylation and the scission of the different bonds present in polymers $(\mathrm{C}-\mathrm{H}, \mathrm{C}-\mathrm{C}, \mathrm{C}=\mathrm{O}, \mathrm{C}-$ $\mathrm{N})$. Some of these bonds such as $\mathrm{C}-\mathrm{N}$ are more heat resistant than the others. It was observed that the second stage degradation of all HU-tetraol-C8 based polymers occured at higher temperatures than the corresponding HU-tetraol monomers (for HU-tetraol-C8: $293{ }^{\circ} \mathrm{C}$ ). The opposite trend was observed for the HU-tetraol-C12 based polymers where the degradation of the HU-tetraol was at $355{ }^{\circ} \mathrm{C}$ versus $330-338^{\circ} \mathrm{C}$ for the polymers. This might be related to the chain length of the used diamine containing higher carbon that the previous one.

The degradation temperatures at $5 \%$ weigh loss of the polymers were slightly lower than those of the corresponding HU-tetraols and they decreased with the amount of DMFD monomers. In the case of HU-tetraol-C $8, \mathrm{~T}_{\mathrm{d}, 5 \%}$ decreased from $211^{\circ} \mathrm{C}$ to $170{ }^{\circ} \mathrm{C}$ while for HU-tetraol-C12 based polymers $\mathrm{T}_{\mathrm{d}, 5 \%}$ decreased from $221^{\circ} \mathrm{C}$ to $180^{\circ} \mathrm{C}$. The presence of residual DMF (shown in NMR) in the samples with 6 eq particularly those based on Hu-tetraol C12 was suspected to catalyze the 
degradation. The amount of formed char above $500^{\circ} \mathrm{C}$ for the all polymers ranged between 3.5 to 5.5 while it was around $0.4 \%$ for the monomers.

Table 2. Thermal properties of the purified monomers and polyesters

\begin{tabular}{lccccc}
\hline Samples & \multicolumn{3}{c}{$\mathbf{T}_{\mathbf{d}, \mathbf{m a x}}$} & $\mathbf{R}_{\mathbf{5 0 0}}{ }^{\circ} \mathbf{C}(\boldsymbol{\%})$ & $\mathbf{T}_{\mathbf{m}}{ }^{*}$ \\
\cline { 2 - 4 } & $\mathbf{1}^{\text {st }}$ & $\mathbf{2}^{\text {sd }}$ & $\mathbf{3}^{\text {th }}$ & & \\
\hline HU-tetraol C8 & 255.1 & 293.6 & 458 & 0.35 & 96.8 \\
HU-tetraol C12 & 268.3 & 355.3 & 461.1 & 0.47 & 122.0 \\
C8-1eq-90 & 244.3 & 330.3 & 449.1 & 2.37 & 106.6 \\
C8-1eq-120 & 245.1 & 333 & 447.1 & 3.27 & 99.2 \\
C8-3eq-120 & 252.6 & 331.8 & 448.1 & 3.47 & 98.5 \\
C8-6eq-120 & 258.6 & 325.1 & 445 & 5.85 & 93.7 \\
C12-1eq-90 & $246-264^{*}$ & 335.3 & 454.1 & 2.01 & 110.8 \\
C12-1eq-120 & 251.0 & 337.3 & 455 & 2.25 & 106.5 \\
C12-3eq-120 & $235-250^{*}$ & 337.3 & 453.1 & 2.95 & 103.3 \\
C12-6eq-120 & 243.0 & 331.5 & 449.5 & 3.65 & 101.0 \\
\hline
\end{tabular}

* These values refer to first calorimetric scan

** Two degradation temperature were detected.

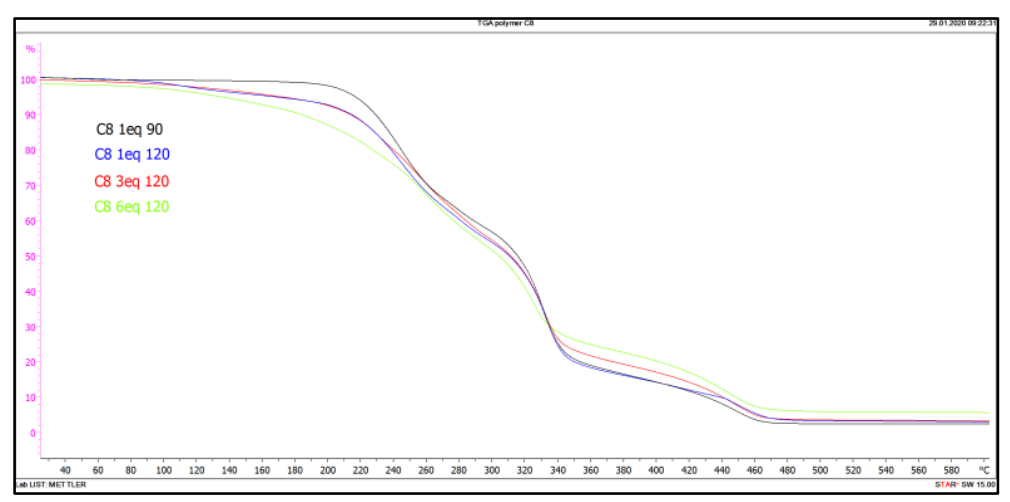




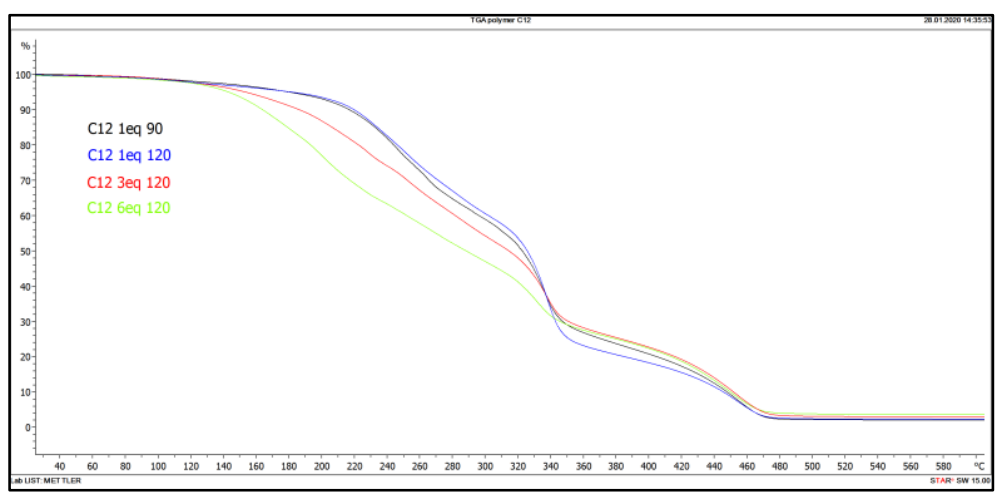

Figure xx. TGA profiles for NIPEUs synthesized at different conditions using the HU-tetraolC8 and HU-tetraol C12.

The thermal properties of the prepared polymer were further analyzed by DSC. The recorded thermograms at the first heating rate of the obtained materials derived from of the HU-tetraol C8 and HU-tetraol C12 combined with different ratio of DMFD are presented in Figure $\mathbf{x x}$ and the the melting temperature $\left(\mathrm{T}_{\mathrm{m}}\right)$ measured are gathered in Table 2. All synthesized polymers exhibited clear melting temperatures showing their semi-crystalline structures. Alike the monomers these crystalline structures were believed to be induced by the hydrogen bond networks formed mainly between the HU-tetraols monomers. For HU-tertraol C 8 based polymers, the melting temperature decreased from 106 to $93{ }^{\circ} \mathrm{C}$ with the increase of the DMFD content and also the temperature. The same trend was observed for HU-tetraol C12 based polymers (from 110 to $101^{\circ} \mathrm{C}$ ), but in this case the melting temperature of all obtained polymers were clearly lower than those of the corresponding monomer HU-tetarol $\mathrm{C} 12\left(122^{\circ} \mathrm{C}\right)$. This behavior could be explained by the flexibility of the long chain of the used diamine in this case which can reduce the hydrogen bonding network while the chain growth of the NIPEUs is progressing. 


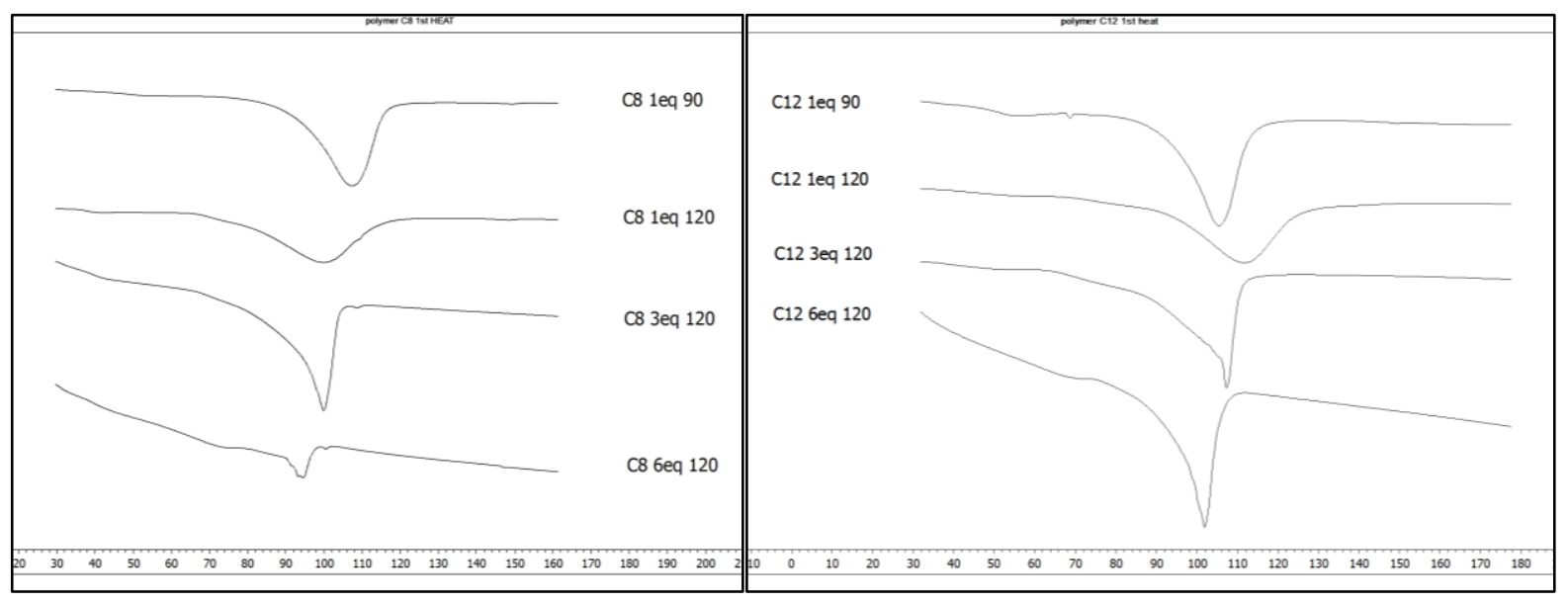

Figure: DSC thermograms obtained at the first heating ramp for NIPEUs synthesized at different conditions using the HU-tetraol- C8 and HU-tetraol C12.

Unlike traditional polyurethanes, neat PHUs are known to undergo dynamic bonding exchanges through transcarbamoylation reactions providing them the capability to be recycled and/or reprocessed. Few studies demonstrated that this vitrimer-like behavior is mainly induced upon heating (ref) but recent study has shown that it can also be mechanically activated under given conditions for some particular molecular architectures (ref). Although very interesting, this behavior along with the hydrogen bonding networks are considered as limiting factors for achieving higher molecular weights for polymerization. Therefore, the development of polymerization strategies to overcome this drawback while preserving this vitrimer-like character is highly sought. In our case, particular attention was given to check the occurrence of this bonding exchange in the new synthesized polymers. Hence after an isothermal ramp at room temperature, a second heating cycle was conducted for all polymers as well as for the monomers in the DSC. Noting that as described in the experimental part, the first heating ramp was stopped at $180{ }^{\circ} \mathrm{C}$ to prevent any thermal degradation and hence molecular changes to avoid any misinterpretation. The recorded DSC of the polymers are depicted in Figure xx (those of the HU- 
tetraol monomers are in Figure SI-2). For HU-tetraol a clear endothermic peak appeared at $62{ }^{\circ} \mathrm{C}$ following by an exothermic peak at $65^{\circ} \mathrm{C}$ before reaching the final melting temperature $86^{\circ} \mathrm{C}$. The presence of such peaks revealed the occurrence of an association-dissociation of bonds that are related to transcarbamoylation reactions already reported for PHUs in the same temperature ranges. In the case of $\mathrm{HU}$-tetraol $\mathrm{C} 12$ an additional small peak was observed at $106{ }^{\circ} \mathrm{C}$ near to the melting temperature $\left(11{ }^{\circ} \mathrm{C}\right)$ confirming the effect of the length of the spacer molecules on the thermal properties of PHUs as previously discussed. In regard to the resulting NIPUEs, similar thermal behavior was observed for all polymers prepared with up to 3 eq of DMFD regardless of the temperature. Endothermic and exothermic peaks were detected prior to the melting temperature. However, for the polymers synthesized with 6 eq of diacids for both HUtetraols, this behavior was annealed because no peak was detected including the peak associated with the melting. In this case the complete dissociation of the hydrogen bond network, which was originally weak, was not reformed most probably hindered by the long chain of spacer and also the expected high molecular weight. Regarding the structural features determined by NMR, one can speculate that the end groups of the NIPEUs particularly the presence of free hydroxyl groups play a key role in the bond exchange phenomenon observed. Indeed, for polymers synthesized with up to 3 eq diacids that bear hydroxyl moieties at their end groups are most likely to undergo bond exchanges. The presence of esterified carboxylic moieties at the end groups of the polymers prepared NIPEUs impede the bond exchanges. The anticipated high molecular weight of these polymers prepared with 6 eq of diacids may also play a role in the restriction of occurrence of bond exchange by limiting the chain mobility. Further in-depth examination is absolutely needed to shed more light on this striking behavior revealed for the first time for such new polyester-urethanes with particular architectures. 


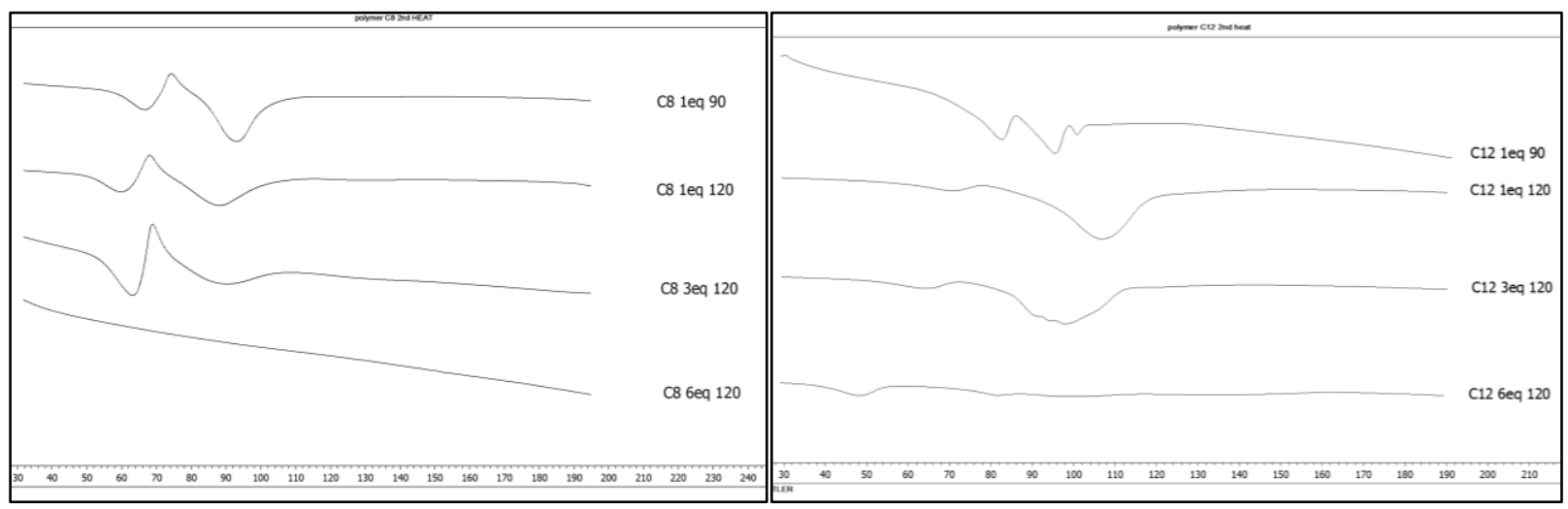

Figure: DSC thermograms obtained at the second heating ramp for NIPEUs synthesized at different conditions using HU-tetraol C8 and HU-tetraol C12.

\section{Conclusions}

Here, we reported for the first time to our knowledge the chain extension through polycondensation of fully bioased polyhydroxylurethanes, used as polyols in combination of sugar-derived furan diacids. The reported consecutive synthetic paths allowed formation of covalent cross-linked isocyanate-free polyester-urethane networks with various furanic molar ratios. The resulting networks exhibited striking thermal behavior upon repetitive heating cycles. Already reported for polyhydroxylurethanes, this behavior, reported herein for the first time for polyester-hydroxyurethanes, is associated with thermal induced bond exchange driven by transcarbamoylation reaction and at less extent to hydrogen bonding network. Such vitrimer-like behavior of this new type of NIPEUs is unique, which can pave the way toward the design a new range of functional green materials. In-depth investigations of this behavior using in-situ NMR analyses and rheological characterization in addition to further thermal scrutiny to provide more insights to better understand this behavior are ongoing.

\section{Funding Sources}


The authors are grateful to the Luxembourg National Research Fond (FNR) for the financial support under CatBiose Project INTER-ANR-FNR n ${ }^{\circ}$ 14/9903334.

\section{Acknowledgment}

We would like to thank Coraline Sirot, Régis Vaudemont and Benoît Marcolini at LIST who continuously provide a friendly and collegial support for thermal and NMR analyses to help us conduct our work. Youssef Habibi would like to express his thanks to Profs Ulrica Edlund and Simona Percec for the kind invitation to contribute to the special issue edited in honor of Prof Ann-Christine Albertsson, the 2019 Anselme Payen Awardee.

\section{References}

1. Akindoyo, J.O., M.D.H. Beg, S. Ghazali, M.R. Islam, N. Jeyaratnam, and A.R. Yuvaraj, Polyurethane types, synthesis and applications - a review. RSC Advances, 2016. 6(115): 114453-114482.

2. Cornille, A., R. Auvergne, O. Figovsky, B. Boutevin, and S. Caillol, A perspective approach to sustainable routes for non-isocyanate polyurethanes. European Polymer Journal, 2017. 87: 535-552.

3. Engels, H.-W., H.-G. Pirkl, R. Albers, R.W. Albach, J. Krause, A. Hoffmann, H. Casselmann, and J. Dormish, Polyurethanes: Versatile Materials and Sustainable Problem Solvers for Today's Challenges. Angewandte Chemie International Edition, 2013. 52(36): 94229441.

4. Bello, D., C.A. Herrick, T.J. Smith, S.R. Woskie, R.P. Streicher, M.R. Cullen, Y. Liu, and C.A. Redlich, Skin Exposure to Isocyanates: Reasons for Concern. Environmental Health Perspectives, 2007. 115(3): 328-335.

5. Bello, D., S.R. Woskie, R.P. Streicher, Y. Liu, M.H. Stowe, E.A. Eisen, M.J. Ellenbecker, J. Sparer, F. Youngs, M.R. Cullen, and C.A. Redlich, Polyisocyanates in 
occupational environments: A critical review of exposure limits and metrics. American Journal of Industrial Medicine, 2004. 46(5): 480-491.

6. Kathalewar, M.S., P.B. Joshi, A.S. Sabnis, and V.C. Malshe, Non-isocyanate polyurethanes: from chemistry to applications. RSC Advances, 2013. 3(13): 4110-4129.

7. Maisonneuve, L., O. Lamarzelle, E. Rix, E. Grau, and H. Cramail, Isocyanate-Free Routes to Polyurethanes and Poly(hydroxy Urethane)s. Chemical Reviews, 2015. 115(22): 12407-12439.

8. Rokicki, G., P.G. Parzuchowski, and M. Mazurek, Non-isocyanate polyurethanes: synthesis, properties, and applications. Polymers for Advanced Technologies, 2015. 26(7): 707761.

9. Błażek, K. and J. Datta, Renewable natural resources as green alternative substrates to obtain bio-based non-isocyanate polyurethanes-review. Critical Reviews in Environmental Science and Technology, 2019. 49(3): 173-211.

10. Carré, C., Y. Ecochard, S. Caillol, and L. Avérous, From the Synthesis of Biobased Cyclic Carbonate to Polyhydroxyurethanes: A Promising Route towards Renewable NonIsocyanate Polyurethanes. ChemSusChem, 2019. 12(15): 3410-3430.

11. Ghasemlou, M., F. Daver, E.P. Ivanova, and B. Adhikari, Bio-based routes to synthesize cyclic carbonates and polyamines precursors of non-isocyanate polyurethanes: A review. European Polymer Journal, 2019. 118: 668-684.

12. Yadav, N., F. Seidi, D. Crespy, and V. D'Elia, Polymers Based on Cyclic Carbonates as Trait d'Union Between Polymer Chemistry and Sustainable CO2 Utilization. ChemSusChem, 2019. 12(4): 724-754.

13. Blain, M., A. Cornille, B. Boutevin, R. Auvergne, D. Benazet, B. Andrioletti, and S. Caillol, Hydrogen bonds prevent obtaining high molar mass PHUs. Journal of Applied Polymer Science, 2017. 134(45): 44958. 
14. He, X., X. Xu, Q. Wan, G. Bo, and Y. Yan, Synthesis and Characterization of DimmerAcid-Based Nonisocyanate Polyurethane and Epoxy Resin Composite. Polymers, 2017. 9(12): 649.

15. Lambeth, R.H. and A. Rizvi, Mechanical and adhesive properties of hybrid epoxypolyhydroxyurethane network polymers. Polymer, 2019. 183: 121881.

16. Asemani, H., F. Zareanshahraki, and V. Mannari, Design of hybrid nonisocyanate polyurethane coatings for advanced ambient temperature curing applications. Journal of Applied Polymer Science, 2019. 136(13): 47266.

17. Cornille, A., J. Serres, G. Michaud, F. Simon, S. Fouquay, B. Boutevin, and S. Caillol, Syntheses of epoxyurethane polymers from isocyanate free oligo-polyhydroxyurethane. European Polymer Journal, 2016. 75: 175-189.

18. Ke, J., X. Li, F. Wang, S. Jiang, M. Kang, J. Wang, Q. Li, and Z. Wang, Non-isocyanate polyurethane/epoxy hybrid materials with different and controlled architectures prepared from a CO2-sourced monomer and epoxy via an environmentally-friendly route. RSC Advances, 2017. 7(46): 28841-28852.

19. Cornille, A., Y. Ecochard, M. Blain, B. Boutevin, and S. Caillol, Synthesis of hybrid polyhydroxyurethanes by Michael addition. European Polymer Journal, 2017. 96: 370-382.

20. Decostanzi, M., C. Bonneaud, and S. Caillol, From hydroxyurethane methacrylates to hybrid nonisocyanate polyurethanes. Journal of Polymer Science Part A: Polymer Chemistry, 2019. 57(11): 1224-1232.

21. Ecochard, Y., J. Leroux, B. Boutevin, R. Auvergne, and S. Caillol, From multi-functional siloxane-based cyclic carbonates to hybrid polyhydroxyurethane thermosets. European Polymer Journal, 2019. 120: 109280.

22. Zabalov, M.V., R.P. Tiger, and A.A. Berlin, Mechanism of urethane formation from cyclocarbonates and amines: a quantum chemical study. Russian Chemical Bulletin, 2012. 61(3): 518-527. 
23. Lombardo, V.M., E.A. Dhulst, E.K. Leitsch, N. Wilmot, W.H. Heath, A.P. Gies, M.D. Miller, J.M. Torkelson, and K.A. Scheidt, Cooperative Catalysis of Cyclic Carbonate Ring Opening: Application Towards Non-Isocyanate Polyurethane Materials. European Journal of Organic Chemistry, 2015. 2015(13): 2791-2795.

24. Flory, P.J., Fundamental principles of condensation polymerization. Chemical Reviews, 1946. 39(1): 137-197. 